\title{
Workplace Innovation Forum: A section in the EJWI
}

\section{Richard Ennals}

\begin{abstract}
Launching a new journal means beginning a distinctive new conversation. Workplace Innovation is about practice, and not just academic theory. The journal needs a place where practice is presented, and can influence the development of theory. Short articles are welcome for the Forum Section in EJWI, facilitating debate and collaboration.
\end{abstract}

Keywords: Collaboration, conversation, dialogue, debate, innovation, practice, workplace 


\section{Conversation}

Traditional publications on Innovation have concentrated on product innovation or process innovation. Increasingly attention has turned to considering people, and ways of working.

"Workplace Innovation" is the name of a conversation which brings together diverse potential partners to reflect on and share experience. It can be seen as exemplifying "learning from differences", when the dialogue partners are engaged in active interventions, with the objective of bringing about change. It is an environment for practical learning.

This account suggests that consultants should not be central actors in Workplace Innovation, selling, and re-selling, solutions from outside the workplace. Workplace Innovation is not a spectator sport. We learn from getting our own hands dirty.

\section{Evidence}

There are also complications when "evidence" is discussed. From inside, there is no opportunity to be detached and objective, with regard to an intervention in which one has personally participated. From outside, how can we describe and quantify what is going on? We demonstrate our response to interventions and conversations by continuing, "going on".

With these reflections we can understand the experience of the European Workplace Innovation Network to date. Each event, in a high profile programme around Europe, represents a new start to the conversation, but with the presence of a core of veterans from the earlier dialogue. The process echoes the growth of the European Union. "The language game is played".

Each actor will of course be influenced by particular "evidence", in their decisions with regard to intervention. The body of evidence needs to constitute an offer they cannot refuse, but in a language they can understand. This goes beyond the terms of detached social science, bolstered by quantification. Rather we may come to see "management as intervention", conducted in line with Action Research, and sustained by reflection.

This view presents problems for those who wish to evaluate success against pre-determined targets, in terms of social media activity, or numbers attending events. The real outcomes of the conversation, at different stages, may be tacit, in terms of changes in attitudes. Change takes time. 


\section{Context}

We should recall that "Workplace Innovation" is framed in the language of European Employment and Social Policy, in which decisions are not simply a matter for managers. There is a context of "social dialogue" and "social benchmarking". This does not imply a uniform set of arrangements across the EU. There is however a common vocabulary which can be used by those within the EU "form of life", to conduct EU "language games".

On this view, we should not expect tight definitions of the content of "Workplace Innovation". Rather, with Kurt Lewin, we should seek to gain understanding of the working of the system through our own efforts to change it.

\section{Explanation and Understanding}

Wittgenstein argued that an "explanation" is whatever has to be said, or written, in order to enable us to "go on". He saw the task of philosophers as "showing the flies the way out of the fly bottle". Here this would be a contribution to Workplace Innovation. There are new ways out.

An event organised by the UK Work Organisation Network (UKWON), or the European Workplace Innovation Network (EUWIN), is like a gathering of old friends at a party. There is much to be said, but it does not all come from the same tradition. It cannot be compiled into a single narrative. Individual conversations tend to be based on shared experience. It neither draws on a consistent scientific base nor contributes significantly to scientific publication.

In a diverse world, it is a significant achievement to frame a language for events which bring partners together. There is an irreducible level of "fuzziness", as people converge from many directions and disciplines, trying to use a common language but with different meanings. A new "form of life" is being constituted, with a distinctive set of "language games", spanning 30 countries.

Official agencies which fund new collaborative programmes can have unrealistic expectations. They will be obliged to evaluate the innovations by the criteria of the past, while being unable to give assurances regarding support in the future. Despite the best intentions of EU project officers, decisions on future EU funding are made by arbitrary selections of external evaluators. The resulting programmes may lack coherence and consistency.

For 20 years there has been a succession of EU networks, consortia and projects: European Work and Technology Consortium, European Work Organisation Network, a series of Framework projects, and now EUWIN. The European Commission provides the bare bones. Flesh needs to be added on a sustainable basis. Structures feel provisional. Support in member countries varies. Relationships and marriages start with encounters and conversations. They depend on the development of trust, which grows incrementally. 


\section{The Fifth Element}

This interpretation of Workplace Innovation highlights the challenges faced by those orchestrating events and projects. It exposes scope for misunderstanding between partners whose background assumptions are very different. There have been creative attempts to build a common structure which all can recognise. At this point we could say that "The Fifth Element" is seen as the tip of a potential iceberg of shared firm ground, with four pillars. Icebergs can melt.

I had some initial epistemological doubts regarding the introduction of Workplace Innovation and "The Fifth Element" as, for example, a stated means of tackling problems of the health of older workers, in the EU WORKAGE project. The core argument is that enlightened management practice benefits workers of all ages. Here, instead of reflecting on past experience, we are suggesting that partially articulated concepts can be used to solve practical problems of which we may know little. It could be wiser to say that there could be active interventions which could then be described in terms of Workplace Innovation. This, however, means missing out a detailed account, in advance, of proposed interventions.

As long as the Workplace Innovation conversation does not include policy makers, little will change. They usually stay at a safe distance, treating the workplace as a "black box". If they fund the inputs for work, they want to evaluate the outputs.

\section{EJWI}

The European Journal of Workplace Innovation (EJWI) could help EUWIN participants to develop an understanding of management and intervention. EJWI could highlight links between management and Action Research, thus relegating social scientific detachment to the dustbin of history. At the same time, this could help to mainstream Action Research, moving on from a disparate archipelago of groups and agendas.

As an open access online journal hosted by the University of Agder, EJWI can contribute to practice, as well as to research at the Department of Working Life and Innovation.

EJWI could include reports from EUWIN events. Links could be made with the new and rapidly growing EUWIN Knowledge Bank of company cases. Readers may learn little from documented cases if they are not themselves involved in practical change projects, with which they can make comparisons. There will be calls for tight definitions, in a world of "family resemblances". I recommend using cases as reference points, and prioritising the use of case studies written from inside. Thus we will see the meaning of the words, in their use.

Each EJWI number can be a tool for Workplace Innovation. Access is free and open. Interactive debate is needed, which goes beyond the formal structure of a conventional academic journal. The Workplace Innovation Forum welcomes contributors! Contributions for the Workplace Innovation Forum should have a maximum length of 1500 words. 


\section{About the author}

Professor Emeritus at Kingston University, Professor at the University of Agder, a director of Workplace Innovation Ltd, and an editor of the European Journal of Workplace Innovation,

England.

E-Mail: richard.ennals@gmail.com 